Research Paper

\title{
Influence of hyperproteinemia on reproductive development in an invertebrate model
}

\author{
Yong-Feng Wang ${ }^{1,2^{*}}$, Xue-Dong Chen ${ }^{1}$ 2 $^{*}$, Guang Wang ${ }^{1,2}$, Qiu-Ying Li ${ }^{1,2}$, Xin-Yin Liang ${ }^{1,2}$, Yang-Hu Sima ${ }^{1,2}$, \\ Shi-Qing $\mathrm{Xu}^{1,2}$ \\ 1. School of Biology and Basic Medical Sciences, Medical College, Soochow University, Suzhou 215123, China. \\ 2. Institute of Agricultural Biotechnology \& Ecology (IABE), Soochow University, Suzhou 215123, China. \\ * Yong-Feng Wang and Xue-Dong Chen contributed equally to this work. \\ $\square$ Corresponding author: Shi-Qing Xu, Email: szsqxu@suda.edu.cn. \\ (1) The author(s). This is an open access article distributed under the terms of the Creative Commons Attribution License (https://creativecommons.org/licenses/by/4.0/). \\ See http://ivyspring.com/terms for full terms and conditions.
}

Received: 2019.01.19; Accepted: 2019.06.09; Published: 2019.08.19

\begin{abstract}
Hyperproteinemia is a severe metabolic disease characterized by abnormally elevated plasma protein concentrations (PPC). However, there is currently no reliable animal model for PPC, and the pathological mechanism of hyperproteinemia thus remains unclear. In this study, we evaluated the effects of hyperproteinemia on reproductive development in an invertebrate silkworm model with a controllable PPC and no primary disease effects. High PPC inhibited the synthesis of vitellogenin and $30 \mathrm{~K}$ protein essential for female ovarian development in the fat body of metabolic tissues, and inhibited their transport through the hemolymph to the ovary. High PPC also induced programmed cell death in testis and ovary cells, slowed the development of germ cells, and significantly reduced the reproductive coefficient. Furthermore, the intensities and mechanisms of high-PPC-induced reproductive toxicity differed between sexes in this silkworm model.
\end{abstract}

Key words: hyperproteinemia; animal model; reproductive development; vitellogenin; programmed cell death

\section{Introduction}

Abnormal plasma protein concentration (PPC) is closely related to clinical mortality [1-4]. Hyperproteinemia is a major metabolic disease characterized by abnormally elevated PPC [5-8], and is clinically common in complications of multiple myeloma [9], renal failure [10], liver disease [11-13], and nematode infections [14]. Hyperproteinemia has also been observed in Leishmania infantum infections [15] and chronic lymph flow ${ }^{[16]}$ in dogs, peritonitis in cats [17], and abdominal abscesses in horses [18].

There have been few reports of the pathological mechanisms and treatments for hyperproteinemia to date [19,20]. However, studies of the relationship between hypoalbuminemia and the physical and chemical properties of blood showed that hyperproteinemia caused blood changes similar to hyperglycemia and hyperlipidemia, leading to increased blood viscosity and to blood circulation and microcirculatory disorders $[6,7,21]$.
Metabolic abnormalities of the circulatory system have been reported to have significant adverse effects on reproductive development. Hypercholesterolemia directly affects fertilization by inducing germ cell apoptosis, worsening Leydig and Sertoli cell secretory functions, reducing sperm production and increasing sperm morphological abnormalities in rabbits [22-24]. Hypercholesterolemia and hyperlipidemia during pregnancy inhibited blastocyst development and altered oocyte metabolism, leading to defects in fetal glucose supply and affecting fetal vascular development [25-27]. Hyperglycemia in pregnant females may inhibit blastocyst development and affect oocyte metabolism via the hexosamine biosynthetic pathway, causing abnormal oocyte and embryo development [25], subsequently increasing perinatal risk [28]. Hyperglycemia has also been shown to damage DNA in germ cells, induce oxidative stress, cause testicular 
structural changes, and affect male reproductive capacity [29,30]. These results highlight the need to evaluate the effects of hyperproteinemia on reproductive development.

There is currently no reliable animal disease model or modeling method for hyperproteinemia in mammals, and we therefore used an invertebrate silkworm model [31-33]. We created an animal model of hyperproteinemia (AM) with no primary disease, in which hyperproteinemia could be generated by controlling PPC levels. We then used this model to investigate the effect of hyperproteinemia on the regeneration of fat bodies in metabolic tissues [19]. Furthermore, because the circulatory system in silkworms is an open system, organs and tissues, including the gonads, are completely immersed in hemolymph, allowing the direct impact of high PPC on the gonads to be observed. In this study, we reconstructed the silkworm model of hyperproteinemia and evaluated the effect of high PPC on reproductive development and the mechanisms responsible.

\section{Materials and methods}

\section{Preparation of animals}

We used the Dazao strain of Bombyx mori in the current study. The larvae were reared conventionally to mature larvae (wandering stage). The spinnerets were then covered with low-melting-point paraffin wax to create a hyperproteinemia model (AM), while silkworms in the control group (CK) were untreated. Both groups were maintained under the same conditions. The experimental process was performed as described previously [19].

\section{Reproduction testing}

Mild hyperproteinemia (mAM) was induced by blocking the silk glands at $6 \mathrm{~h}$ after the wandering stage, thus causing approximately $75 \%$ of the silk protein to be retained in the silk gland. We then investigated the effect of high PPC on the general fecundity of mated pairs $(n=5$ control females and n=11 with mild hyperproteinemia), based on oviposition performance in females (total eggs laid per female, including unfertilized and fertilized eggs), and male fertility (rate of fertilized eggs).

\section{Investigation of gonadal development}

Testes ( $\mathrm{n}=3$ animals) and ovaries ( $\mathrm{n}=3$ animals) were removed from silkworms at the indicated times after modeling, placed in DEPC water, soaked in $4 \%$ paraformaldehyde and used to make paraffin sections. The samples were dewaxed in xylene $(10$ min, twice), followed by $100 \%, 90 \%, 80 \%$, and $70 \%$ ethanol, and ultrapure water for $10 \mathrm{~min}$ each, at room temperature. Sections were stained with hematoxylin-eosin (HE) and used to evaluate gonad development. Silkworm body weights and gonad weights ( $n=6$ animals) were recorded and the gonad somatic index (GSI = weight of gonad/body weight) was determined at 48,96 , and $192 \mathrm{~h}$ after modeling.

\section{Spermateleosis}

Spermateleosis was affected by the duration of exposure to high PPC in vivo and the duration of culture without high PPC in vitro. The animals $(n=6$ animals) were treated as described previously [34]. Testes were isolated using surgical forceps at 48,96 , or $192 \mathrm{~h}$ after modeling, and washed three times with pre-cooled physiological saline and culture medium to eliminate adherent hemocytes. The spermatocysts were then released from each testis into the culture medium using forceps, transferred to a 24-well plate, and cultured for $72 \mathrm{~h}$ at $25^{\circ} \mathrm{C}$ without high PPC in Grace's insect cell culture medium supplemented with $10 \%$ silkworm hemolymph and appropriate concentrations of antibiotics [34]. The numbers and morphology of the developing spermatocysts were then observed.

\section{Western blotting}

Proteins were extracted from Bombyx $(n=3$ animals) fat bodies in RIPA buffer at 48, 96, and $192 \mathrm{~h}$ after modeling. The total protein concentration was determined using a BCA Protein Assay Kit (Solarbio, Beijing, China), and $100 \mu \mathrm{g}$ of protein extracts were subjected to $10 \%$ sodium dodecyl sulfate-polyacrylamide gel electrophoresis and transferred to a polyvinylidene difluoride membrane using a semi-dry transfer film. The membrane was blocked with a blocking solution, followed by incubation with purified anti-vitellogenin (Vg), anti-30Kc19 (1:1000), or anti-tubulin (1:5000) antibody (Cell Signaling Technology, Beverly, MA, USA), and then washed and incubated with horseradish peroxidase (HRP)-labeled anti-rabbit IgG (Bioworld Technology, Minneapolis, MN, USA). The membranes were then photographed using an EZ-ECL chemiluminometer Detection Kit for HRP (Biological Industries, Kibbutz Beit-Haemek, Israel) after $1 \mathrm{~min}$ in the dark at room temperature. The resulting images were processed and analyzed.

\section{Real-time polymerase chain reaction analysis}

Gonads, hemolymph, and fat bodies were removed from the silkworms at the indicated time after modeling. Each tissue sample was mixed from three individual silkworms. Transcript levels of $\mathrm{Vg}$ $(\mathrm{BmVg}), \quad 30 \mathrm{~K}$ proteins (Bm30Kc19), 20-hydroxyecdysone receptor (BmEcR), $\mathrm{Vg}$ receptor $(\mathrm{BmVgR})$, early transcription factor $74 \mathrm{a}(\mathrm{BmE74A})$, 
autophagy-related genes (BmAtg6 and BmAtg8), and an apoptosis initiation-related gene (BmDronc) were analyzed by quantitative real-time polymerase chain reaction (qRT-PCR). a-Tubulin was used as a reference gene. qRT-PCR was performed in a $20-\mu l$ reaction solution using an ABI StepOnePlus ${ }^{\mathrm{TM}}$ real-time PCR system (Ambion, Foster City, CA, USA). Total RNA was extracted by traditional methods for qRT-PCR, and qRT-PCR was performed as described previously ${ }^{[19]}$ using the primers listed in Table S1.

\section{Gonad staining}

Reactive oxygen species (ROS) were stained using a ROS Assay Kit (Solarbio, Beijing, China), as described previously (Yan et al., 2016). Silkworm ( $n=3$ animals) gonads were isolated at the appointed time and collected in normal saline $(0.7 \% \mathrm{NaCl})$ to avoid exposure to air, quickly placed into ROS-staining solution for $15 \mathrm{~min}$ at $37^{\circ} \mathrm{C}$, and then washed three times with saline in the dark. After washing, the gonads were placed on a slide (repeated in triplicate) and green fluorescence from the ROS was observed under a fluorescence microscope (Olympus BX51, Tokyo, Japan).

Gonad sections were dewaxed and used for terminal deoxynucleotidyl transferase dUTP nick end labeling (TUNEL) and monodansylcadaverine (MDC) staining using an In Situ Cell Death Detection Kit (TMR Red, Roche, Indianapolis, IN, USA) and MDC staining Kit (Solarbio, Beijing, China), respectively according to their manufacturers' instructions. TUNEL and MDC staining solutions were added to the biopsy tissues (repeated in three tissue sections) for $1 \mathrm{~h}$ at $37^{\circ} \mathrm{C}$ in the dark and the tissue sections were then washed three times in phosphate-buffered saline for $5 \mathrm{~min}$ each. Red fluorescence from the TUNEL assay and green fluorescence from the MDC assay were observed under an Olympus BX51 fluorescence microscope.

\section{Results}

\section{Impact of hyperproteinemia on reproductive development in silkworms}

We previously showed that silkworm larvae with hyperproteinemia (AM) underwent slower metamorphosis after the wandering stage, with no individuals completing metamorphosis and all dying before eclosion [19]. We therefore modified this previous method to allow us to obtain adult silkworms and to investigate the impact of high PPC on their reproductive development, using animals with mild hyperproteinemia (mAM). The PPC level was restored in mAM after $192 \mathrm{~h}$, but was increased rapidly in AM, while the PPC levels in both groups AM and mAM are increased steadily before 192h (Fig.S1). Although the rate of metamorphosis in mAM silkworms was still reduced, $60 \%$ of individuals developed into pupae at $72 \mathrm{~h}$ after modeling, and $20 \%$ developed into adults at $312 \mathrm{~h}$ after modeling.

We investigated the fertilization and development of eggs laid by adult mAM silkworms. Eggs in the control group developed fully and showed consistent size and color (dark brown), with very few unfertilized yellow eggs. In contrast, there were many unfertilized yellow eggs and abnormal light-colored eggs in the mAM group (Fig. 1a). The number of eggs laid by females in the mAM group was $14.1 \%$ lower than in the CK group (Fig. 1b), and the rate of unfertilized eggs was increased from (1.1 \pm $0.65) \%$ in the CK group to $(10.7 \pm 7.2) \%$ in the $\mathrm{mAM}$ group (Fig. 1c). These results indicated that high PPC had significant adverse effects on egg quantity and quality in silkworms, suggesting that hyperproteinemia at the stage of germ cell development adversely affected adult reproduction in silkworms.

To study the mechanism whereby high PPC affected oviposition and fertilization, we reconstructed an animal model of hyperproteinemia (AM) as described by Chen et al. (2018) [19] and investigated the effect of hyperproteinemia on gonad development.

Silkworm testes include four spermatogenic rooms filled with developing spermatocysts [34]. At 48 $h$ after modeling, we observed a few early developmental stage spermatocysts and numerous late developmental stage spermatocysts in the spermatogenic rooms in CK silkworms during spermiogenesis and spermatodesm (Fig. 2a, 2c). In contrast, we observed numerous early developmental stage spermatocysts in the spermatogenic rooms, but few late developmental stage spermatocysts in the center of the spermatogenic rooms in the AM group, as well as some dysplastic spermatocysts with tightly aggregated nuclei (Fig. 2b, 2d). At 192 h after modeling, the spermatogenic rooms in CK silkworms were filled with sperm released from mature spermatocysts, and very few late developmental stage spermatocysts undergoing spermiogenesis and spermatodesm were observed (Fig. 2e, 2g). In contrast, the spermatogenic rooms in AM silkworms were filled with cacoplastic late developmental stage spermatocysts (Fig. 2f, 2h). Although there was no significant difference in the morphology or weight of the testes between the AM and CK group at $192 \mathrm{~h}$ after modeling (Fig. S2b), but the comparable GSI was significantly lower in the AM compared with the CK group at 48, 96, and 192 h (Fig. 2o). These results 
indicate that hyperproteinemia affected the development of the testis and inhibited sperm formation.

After the oogonia proliferated into primary oocytes in the oviduct in CK silkworm ovaries, each primary oocyte proliferated into eight cells, forming an egg chamber with an oocyte and seven nurse cells. The oocyte absorbed nutrients from the trophoblast

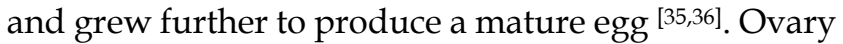
weights in female AM silkworms at $48 \mathrm{~h}$ after modeling (Fig. S2b) were lower than in the CK group, and the development of the germ cells in ovarian tissue was slower than in the CK group, as shown by HE staining (Fig. 2i, 2j, 2k, 2l). The GSI was significantly lower in the AM group at 48-192 h after modeling compared with the CK group (Fig. 2o). At $192 \mathrm{~h}$, the ovary was fully developed in the CK group and the egg tube was filled with formed eggs, indicating a mature adult ovary (Fig. $2 \mathrm{~m}, 2 \mathrm{2}$ ). In contrast, eggs in the AM group remained at the same developmental level as at $48 \mathrm{~h}$ after modeling (Fig. 2n, $2 p)$. These results showed that ovary growth was slower in AM than in CK silkworms, indicating that hyperproteinemia inhibited ovary development and the formation of eggs in silkworms.

We assessed the impact of high PPC exposure on male germ cell development quantitatively by in vitro culture of spermatocysts, as described previously [34]. Normal seminal vesicles can undergo the whole sperm development process from spermatogonia to mature sperm in vitro, namely by completing the three developmental stages: primary spermatocytes, spermatocysts during spermiogenesis, and spermatodesm (Fig. 3a).

Testes were removed from male silkworms at 48, 96, and $192 \mathrm{~h}$ after hyperproteinemia modeling and cultured in vitro for $192 \mathrm{~h}$. Seminal vesicle growth and development were adversely affected as indicated by increased apoptosis, deformity, and membrane damage. Typical dysplastic spermatocysts were seen during the three developmental stages from primary spermatocytes to mature sperm: primary spermatocytes, spermatocysts during spermiogenesis, spermatodesm (Fig. 3b).

Testes were also removed from male silkworms at 48, 96, and $192 \mathrm{~h}$ after hyperproteinemia modeling, for in vitro culture of spermatocysts for $48 \mathrm{~h}$. Seminal vesicles in the CK group developed normally with the formation of mature sperm bundles, and seminal vesicles with typical dysplasia were rare (Fig. 3c). There was no evidence of dysplastic spermatogenesis in the AM group at $48 \mathrm{~h}$ after modeling, but dysplastic and necrotic seminal vesicles were clearly observed after $48 \mathrm{~h}$ of in vitro culture. Furthermore, AM testes removed at $192 \mathrm{~h}$ after modeling showed many spermatozoa with dysplasia, atrophy, and necrosis, and subsequent culture in vitro for $48 \mathrm{~h}$ resulted in the death of most spermatocysts (Fig. 3c and Fig. S3).
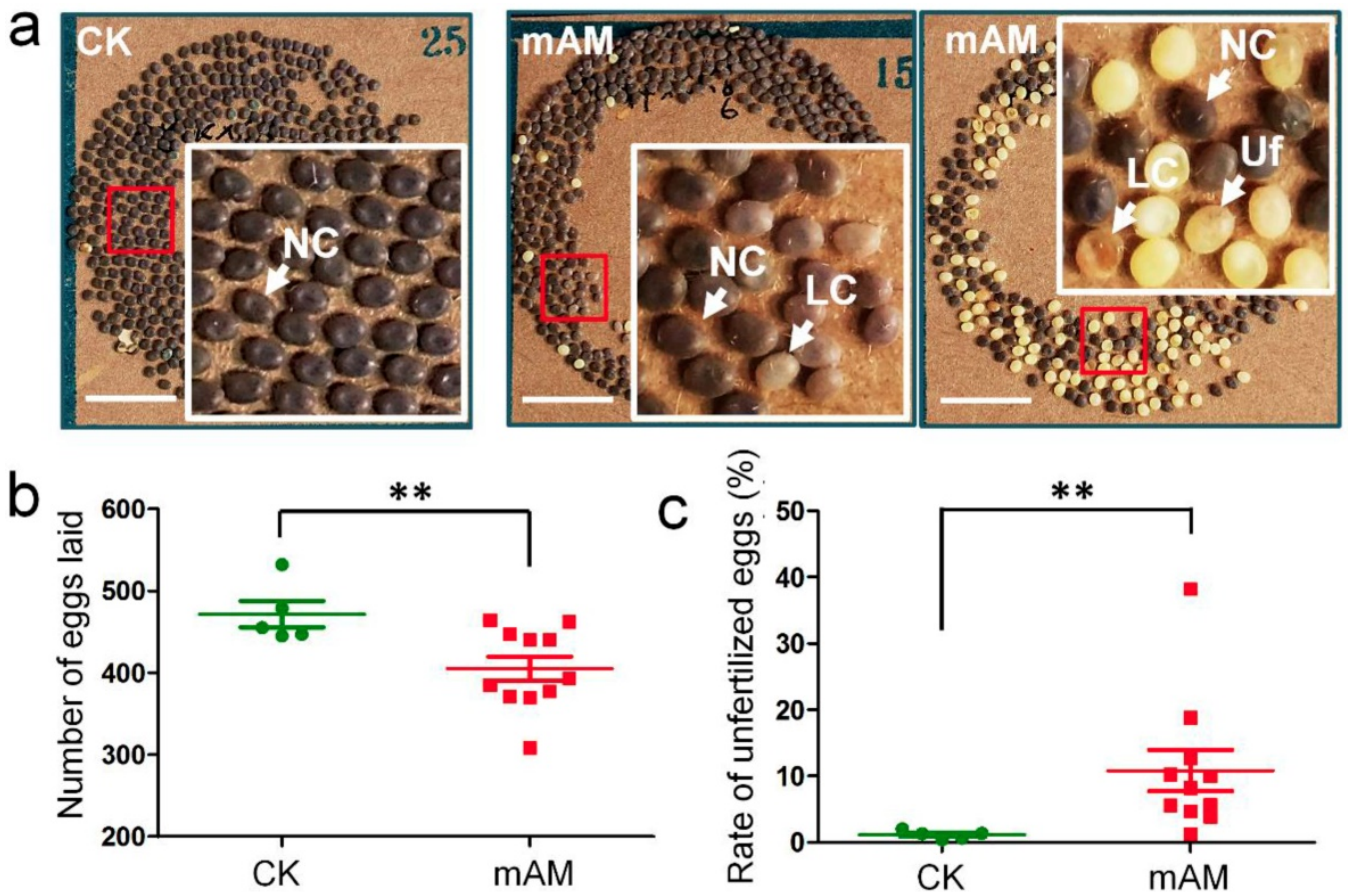

Figure 1. Eggs laid by adult female silkworms. (a) Morphologies of eggs laid by control (CK) females and by females with mild hyperproteinemia (mAM). Mild hyperproteinemia was induced $6 \mathrm{~h}$ after the wandering stage by blocking the spinnerets, resulting in retention of approximately $75 \%$ of the silk protein in the silk gland. NC, natural color eggs; LC, light color of abnormally developed eggs; Uf, unfertilized eggs. (b) Number of eggs laid. (c) Rate of unfertilized eggs. *P<0.05; **P<0.01 between control and $m A M$ groups $(n=5$ female adults in control and $n=11$ in $m A M)$. Bar $=1 \mathrm{~cm}$. 

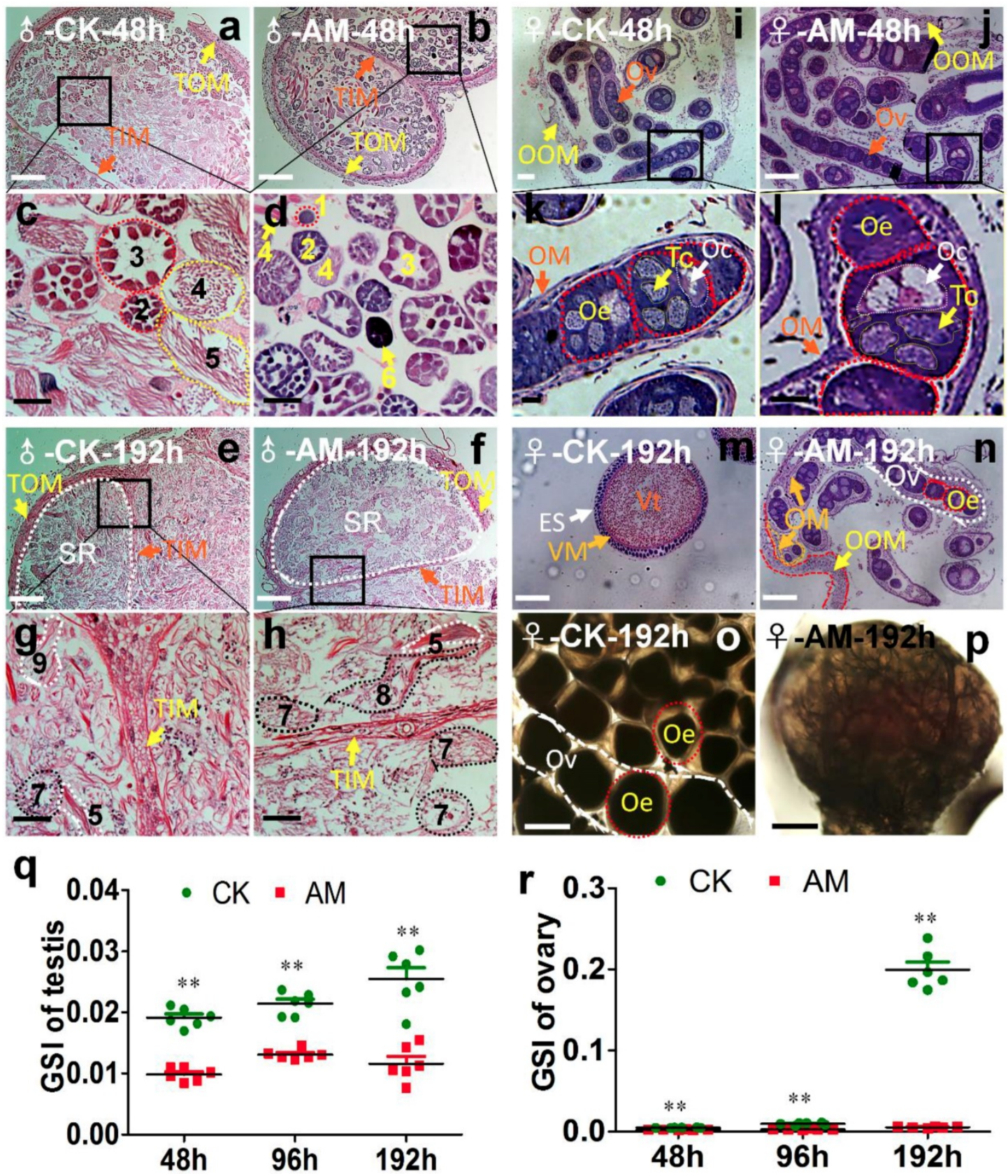

Figure 2. Impact of hyperproteinemia on gonad development. (a-n) Sections of gonads stained by hematoxylin-eosin at 48 and $192 \mathrm{~h}$ after modeling. (o, p) Ovaries under cover glass at $192 \mathrm{~h}$ after modeling. TOM, outer testis membrane; TIM, inner testis membrane; SR, spermatogenic room. Numbers 1-3 indicate early developmental stage spermatocysts during the 32-, 64-, and 128-primary spermatocyte stages, respectively; 4 and 5 indicate late developmental stage spermatocysts during spermiogenesis and spermatodesm, respectively; 9 indicates the release of sperm from mature spermatocysts; 6 indicates cacoplastic spermatocysts during early developmental stage; and 7 and 8 indicate cacoplastic spermatocysts during spermiogenesis and cacoplastic spermatodesm, respectively. Ov, ovarioles; OOM, ovarian outer membrane; OM, ovariole membrane; Oe, ooecium; Oc, oocyte; Tc, trophocyte; Vt, vitellin; VM, vitelline membrane; ES, egg shell. ( $\mathrm{q}$ and r) Gonadosomatic index (GSI) was determined at 48, 96 , and $192 \mathrm{~h}$ after modeling. $* * P<0.01$ between the $A M$ and control groups ( $n=6$ repeated animals).

Dysplastic and necrotic seminal vesicles increased in line with the duration of in vitro culture in the AM group, irrespective of when the testes were removed (Fig. S3). These results indicated that exposure of male gonads to a high-protein hemolymph environment had significant adverse effects on the development of the seminal vesicles, even after they were removed from the high PPC environment, indicating cumulative and delayed toxicity in silkworm gonads.

\section{Hyperproteinemia impacts synthesis and transport of female vitellogenin}

We investigated the mechanism whereby high PPC hindered the formation of silkworm eggs by assessing changes in the expression of genes and proteins involved in vitellogenin $(\mathrm{Vg})$ synthesis [36,37]. $\mathrm{Vg}$ mRNA levels in the fat body of metabolic tissues continued to increase during metamorphosis (48-192 h) in CK group silkworms, but remained low in the 
AM group (Fig. 4a). 30Kc19 gene transcription was also significantly down-regulated in the AM compared with CK group (Fig. 4b). Changes in $\mathrm{Vg}$ and $30 \mathrm{Kc} 19$ protein levels (Fig. 4f, 4g, 4h) determined by western blotting confirmed that $\mathrm{Vg}$ protein levels were significantly lower in the AM compared with the CK group, while 30Kc19 protein levels were also significantly down-regulated in the middle and late stages (96 and $192 \mathrm{~h}$ ) of modeling.

Further investigation revealed that transcription of the $\mathrm{Vg}$ receptor $(\mathrm{VgR})$ gene was also significantly down-regulated in the AM silkworm ovary (Fig. 4c). Furthermore, transcription of hydroxyecdysone receptor $(\mathrm{EcR})$, which regulates the transport of $\mathrm{Vg}$ from the synthetic tissue in the fat body to the ovary, and transcription of the downstream effector gene E74, were both significantly down-regulated in the hemolymph at $48 \mathrm{~h}$ after modeling, but showed significant compensatory up-regulation at 96 and 192 $\mathrm{h}$ after modeling (Fig. 4d, 4e). Moreover, expression levels of EcR and E74, which are related to ovarian development, were significantly up-regulated at 48 and $96 \mathrm{~h}$ after modeling, and then significantly down-regulated at $192 \mathrm{~h}$, but with phase delays in AM silkworms (Fig. 4d, 4e).

The above results indicated that high PPC inhibited the synthesis of $\mathrm{Vg}$ and the silkworm egg-storage protein $30 \mathrm{~K}$ in the female fat body, inhibited the expression of ovarian $\mathrm{VgR}$ via the endocrine pathway, and reduced the transport and accumulation of proteins required for reproduction in the ovary.

\section{Hyperproteinemia increases programmed cell death in silkworm gonads}

We further investigated the mechanism whereby high PPC affected the reproductive development of silkworms in terms of programmed cell death (PCD).

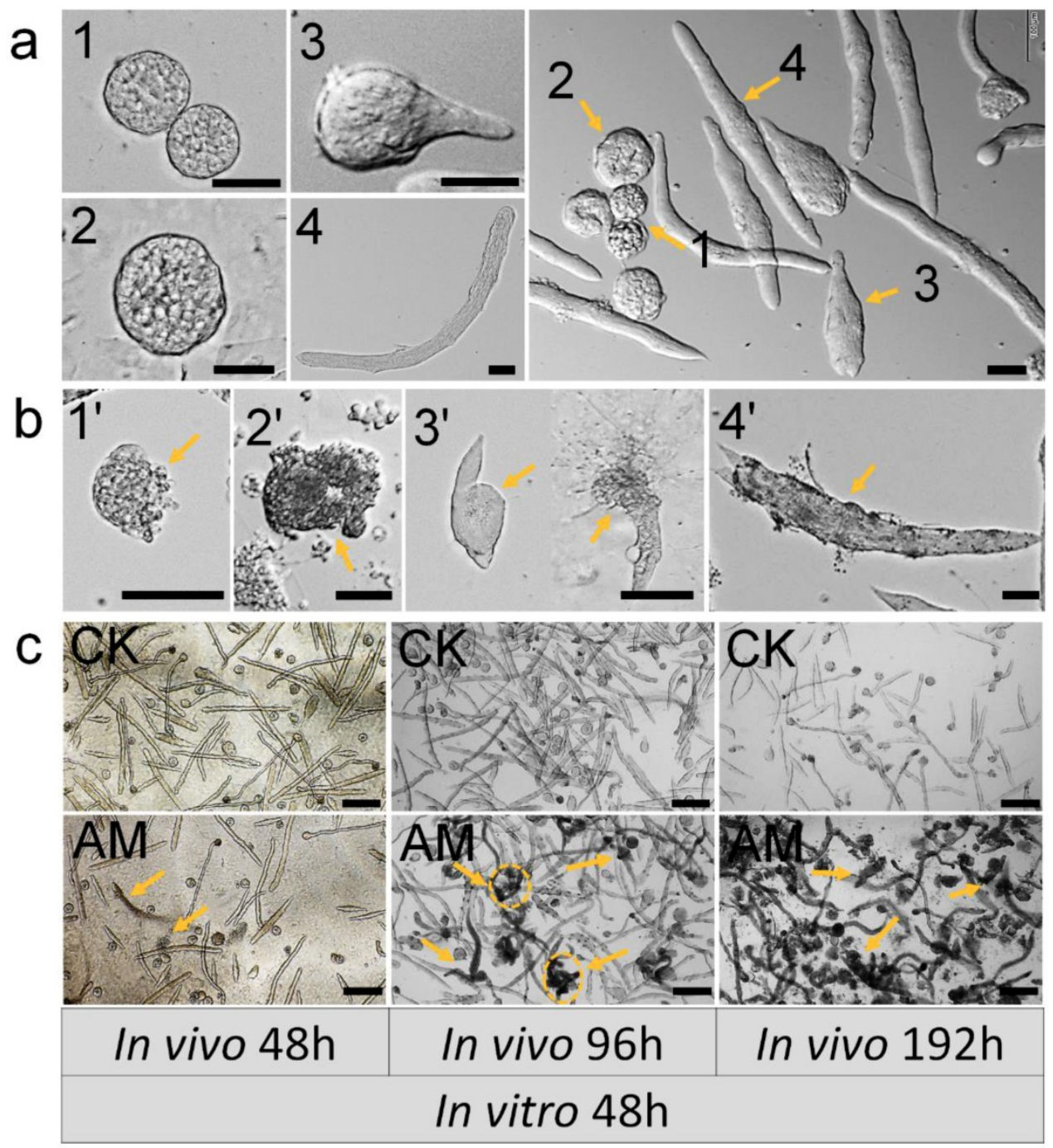

Figure 3. Impact of hyperproteinemia on spermateleosis in Bombyx mori. (a) Natural morphology of spermatocysts. Numbers 1 and 2 indicate 64-, and 258-stage primary spermatocytes in spermatocyst, respectively; 3 indicates spermatocysts during spermiogenesis; and 4 indicates spermatodesm. (b) Cacoplastic morphology of spermatocysts characterized by apoptosis, malformation, and damaged membrane. Numbers $6-9$ indicate cacoplastic spermatocysts corresponding to 1-4 in (a). (c) Spermateleosis was affected by the duration of high-PPC exposure in vivo (i.e., time between model establishment in silkworm larvae and removal of testes). Arrows indicate dysplastic seminal vesicles. Testis were removed at 48,96 , and $192 \mathrm{~h}$ after modeling for in vitro culture for $48 \mathrm{~h}$. Bars $=50 \mu \mathrm{m}$ in (a) and (b) and $200 \mu \mathrm{m}$ in (c). 
a

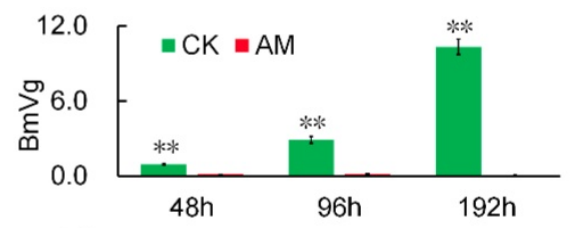

b

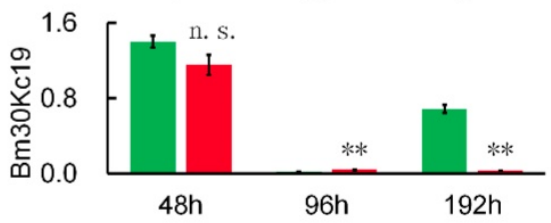

C

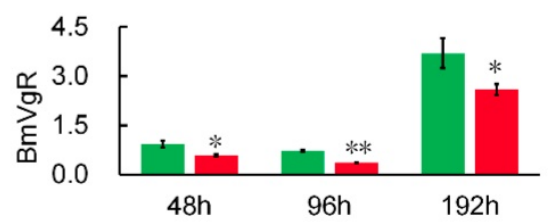

d

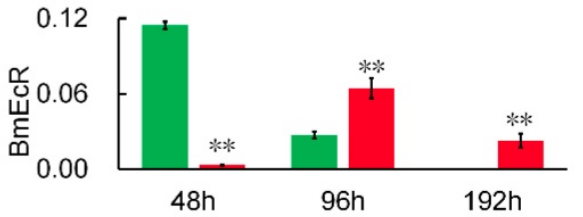

e

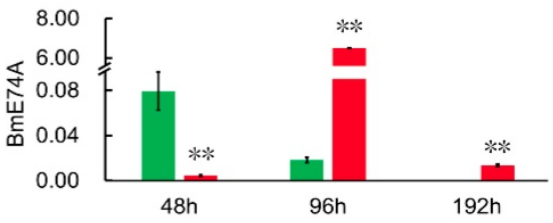

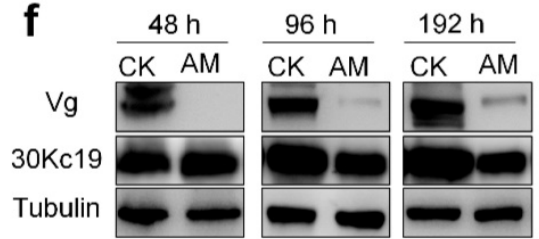

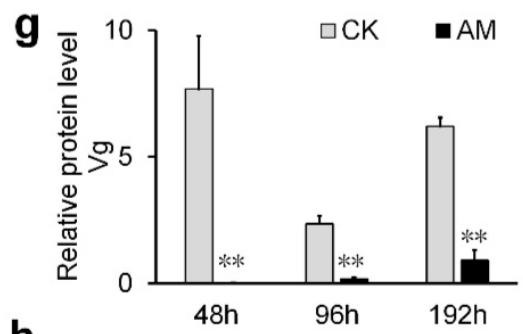

h

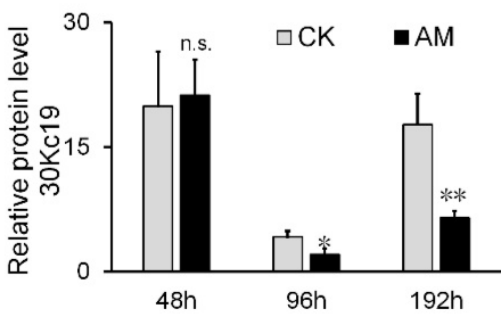

Figure 4. mRNA levels of (a) $\mathrm{BmVg}$ and (b) $\mathrm{Bm} 30 \mathrm{Kcl} 19$ genes in fat body, (c) VgR gene in ovary, and (d) EcR and (e) E74A genes in hemolymph. (f-h) Vg and 30K proteins in fat bodies detected by western blotting. Fat bodies and ovaries were removed from female silkworms at 48,96 , and $192 \mathrm{~h}$ after modeling. $* \mathrm{P}<0.05$; $* * \mathrm{P}<0.01$; n.s., no significant difference between the two groups.

Acidic substances in autophagic vacuole produced by MDC staining is considered a reliable method of assessing the degree of autophagy [38,39,40]. Our MDC staining results showed that green fluorescence associated with autophagy were significantly increased in gonad cells from AM silkworms at 48-192 $\mathrm{h}$ after modeling, in a time-dependent manner (Fig. 5a, 5b). This suggested that high PPC induced autophagy in silkworm gonad cells. To validate the effects of MDC staining, we investigated the mRNA levels of BmAtg6 and BmAtg8, which are involved in the regulation of autophagy [39,41-43]. BmAtg6 and BmAtg8 mRNA levels were significantly up-regulated in AM compared with CK silkworm ovaries, with the change in BmAtg6 occurring before that of BmAtg8 (Fig. 5e, 5f).

Transcription of BmAtg6 and BmAtg8 in testis cells from male silkworms were also significantly up-regulated in the AM group at $48 \mathrm{~h}$ after modeling, but down-regulated after $96 \mathrm{~h}$, with the change in BmAtg8 preceding that of BmAtg6 (Fig. 5c, 5d). These results suggested that high PPC may induce autophagy of gonad cells differently in male and female silkworms.

It has been reported that TUNEL staining is a reliable method of assessing the degree of apoptosis [44,45]. Thus, we also investigated the effects of high PPC on apoptosis in gonad cells by TUNEL staining. Apoptosis, indicated by red fluorescence, was detected at $48 \mathrm{~h}$ after modeling (Fig. 6a). Apoptosis was increased in AM compared with CK silkworms, and was greater in male compared with female gonads. TUNEL staining was enhanced at $192 \mathrm{~h}$ after modeling compared with $48 \mathrm{~h}$ regardless of sex, indicating a time-dependent effect of high PPC-induced apoptosis (Fig. S4).

Transcript levels of the apoptosis-initiating gene BmDronc were similar in AM and CK ovaries at $48 \mathrm{~h}$ after modeling, but were higher in AM ovaries after 48 h (Fig. 6b). While BmCaspase-1 mRNA levels were significantly up-regulated at 48, 96 and $192 \mathrm{~h}$ after modeling (Fig. 6d). BmDronc and BmCaspase-1 mRNA levels in the testis were significantly up-regulated at 48 and $96 \mathrm{~h}$ after modeling, but were significantly down-regulated compared with the CK group (Fig. 6c, 6e). These results suggest that high PPC enhanced the apoptosis regulatory signal in gonad cells and further confirmed that high PPCinduced PCD level are different in ovary and testis cells. 
a
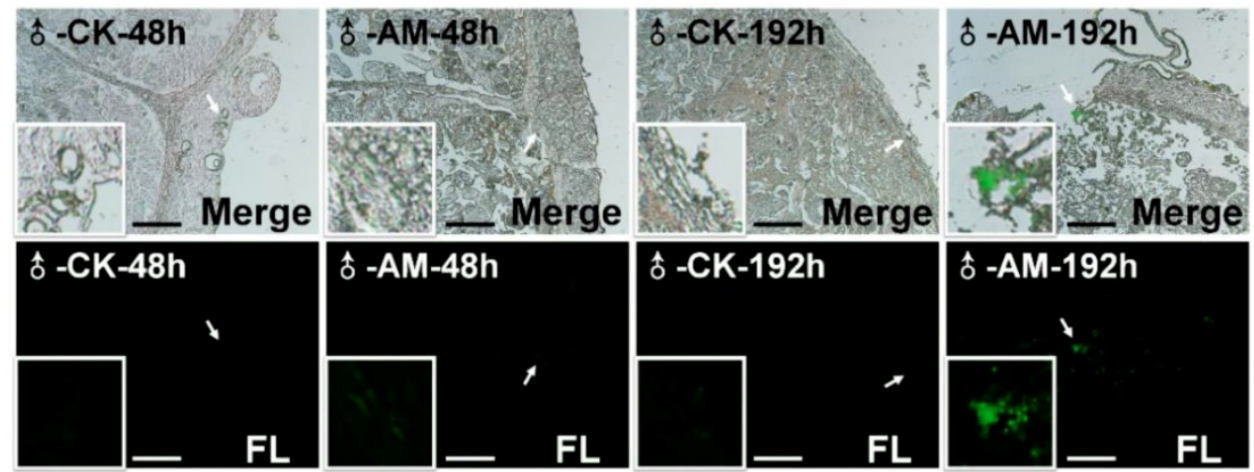

b
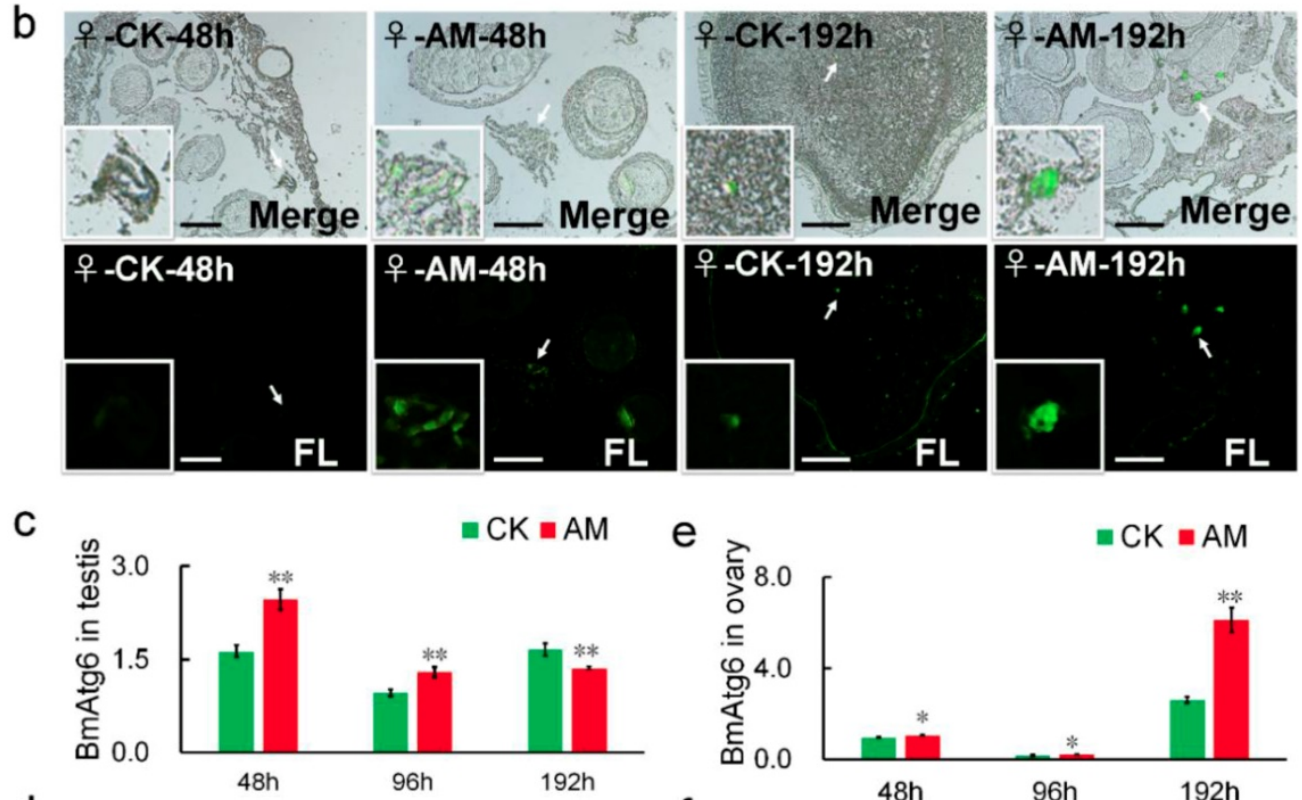

d
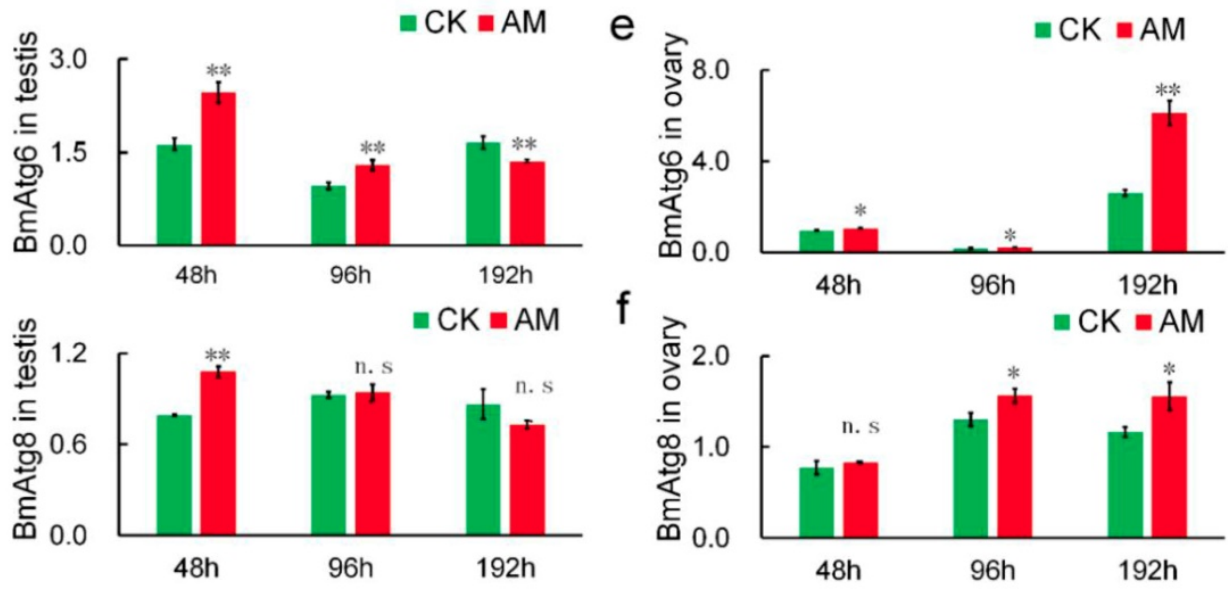

Figure 5. Changes in the levels of autophagy in testes and ovaries. Autophagy of silkworm testis (a) and ovary (b) cells at 48 and $192 \mathrm{~h}$ after modeling, demonstrated by MDC staining. (c-f) mRNA levels of autophagy-related genes BmAtg6 and BmAtg8 in gonad cells from silkworm at $48-192 \mathrm{~h}$ after modeling. $* \mathrm{P}<0.05 ; * * \mathrm{P}<0.01$; $\mathrm{n} . \mathrm{s}$., no significant difference between the two groups. Bar $=100 \mu \mathrm{m}$

We clarified the role of high PPC in the induction of PCD in silkworm gonad cells by examining ROS levels (Fig. 7). ROS plays an important role in maintaining cell homeostasis [34, 46-48]. ROS levels in ovary sections (indicated by green fluorescence) were increased after $96 \mathrm{~h}$ of modelling compared with the CK group; however, ROS were not clearly observable at other times. ROS levels in male testis were similarly low in CK and AM tissue sections. These results indicate that high PPC induced PCD in silkworm gonad cells, but that this was not completely dependent on ROS, at least in male gonads.

\section{Discussion}

\section{Sex difference in reproductive toxicity of hyperproteinemia in silkworms}

There have been few reports of the effects of hyperproteinemia on the reproductive system of humans and animals to date. In this study, we created a silkworm model of mild hyperproteinemia (mAM) and confirmed that high PPC significantly reduced the adult reproductive coefficient and fertilization rate. We also examined the effect of high PPC on reproductive system development using our earlier hyperproteinemia model (AM), and showed that gonad coefficients were significantly reduced in both 
female and male silkworms, with reduced rates of germ cell development. Furthermore, male silkworms were more sensitive to PPC than females. These results indicate the further studies are needed to examine the effects of hyperproteinemia on male reproductive toxicity.

Numerous studies have confirmed that cells can produce oxidative stress and PCD in response to diseases, including metabolic diseases such as hypertension and hyperglycemia, and malignant tumors such as colorectal cancer ${ }^{[49-52]}$. PCD, including apoptosis and autophagy, plays an important role in maintaining homeostasis [53]. In the current study, high PPC induced autophagy and apoptosis in silkworm gonad cells, with differences in both intensity and mechanism between the sexes, including significant differences in ROS levels. Previous studies indicated that the protective function of autophagy was superior to its potential cytotoxic effects [54], and increased levels of autophagy can remove mitochondria and proteins from ROS damage [55,56]. In Fig. 5, the expression of BmAtg6 and BmAtg8 were lower in testes of AM at 192h, while the MDC staining revealed that autophagy was significantly upregulated in AM. The results of a similar lack of coordination were found in Fig.6 between BmDronc and BmCaspase- 1 mRNA levels and TUNEL staining revealed that apoptosis. These results suggested that testis cells are reduced autophagy/apoptosis signal strength, though cells have been a certain amount of autophagy/apoptosis in AM at 192h. We hypothesized that PPC increased rapidly in female silkworms with hyperproteinemia, and gonad cells maintained homeostasis by initiating autophagy through an increased ROS oxidative stress response and further cell death (Fig. 8). a
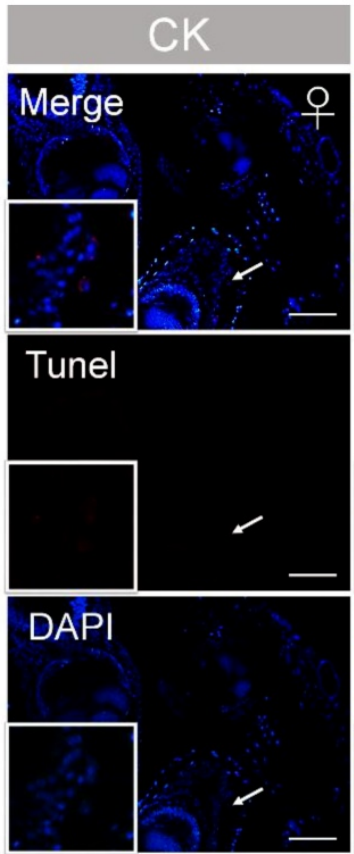

b
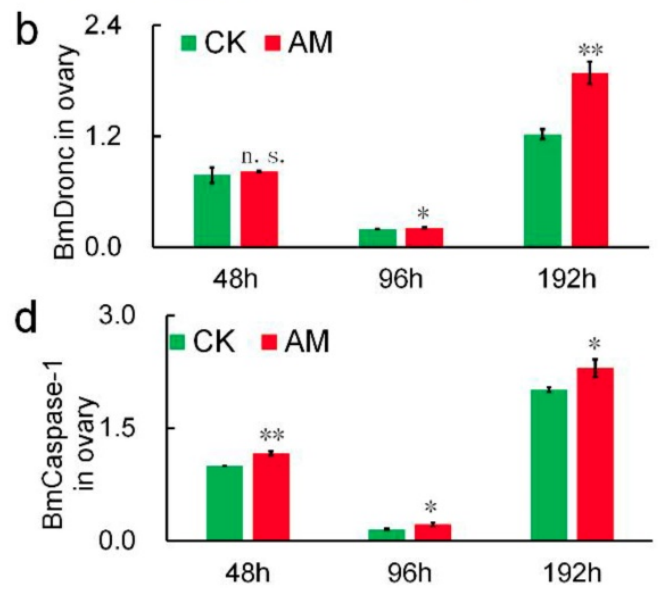
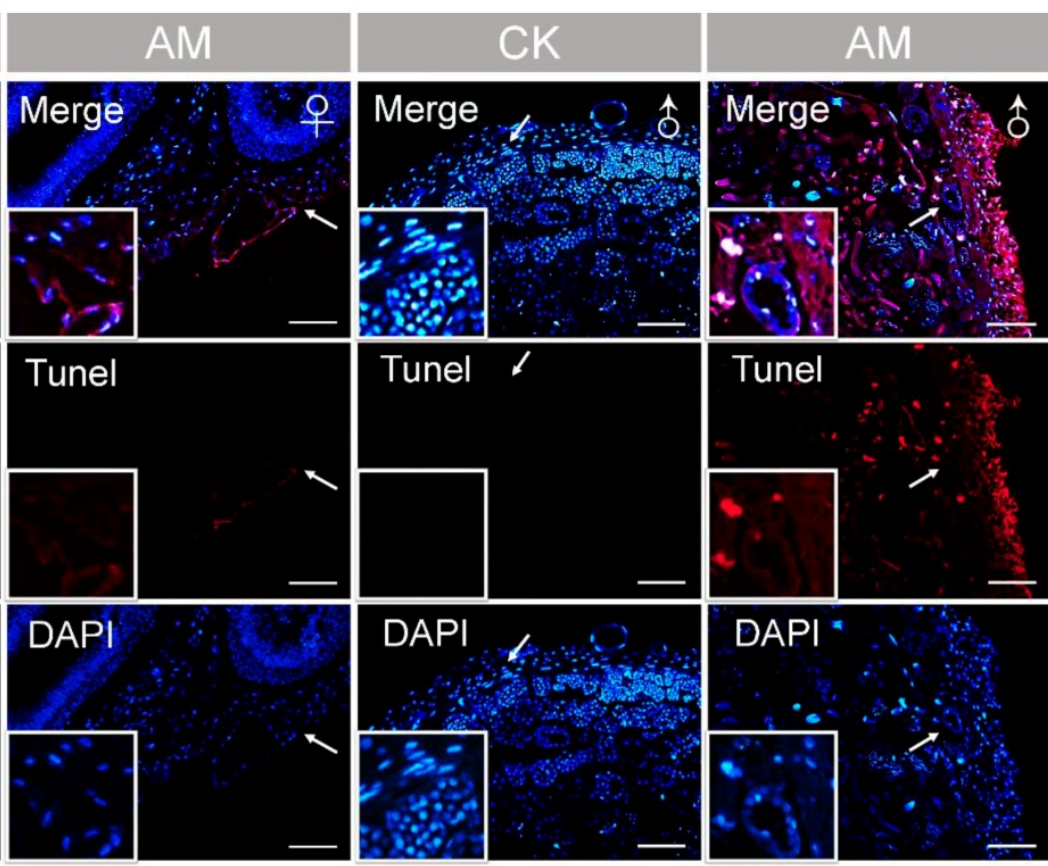

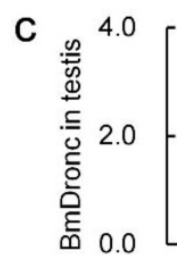
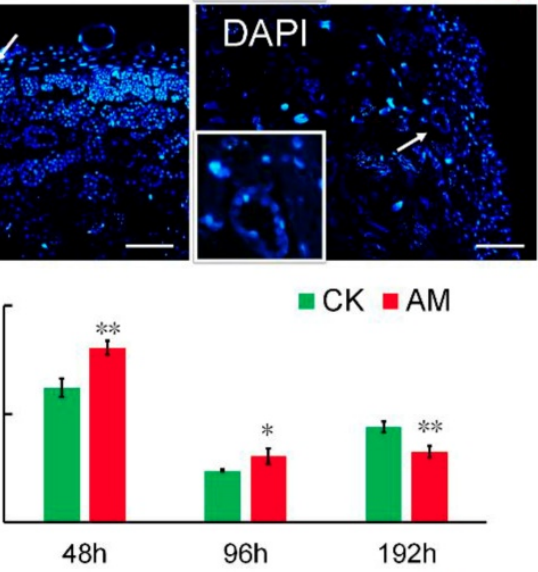

e

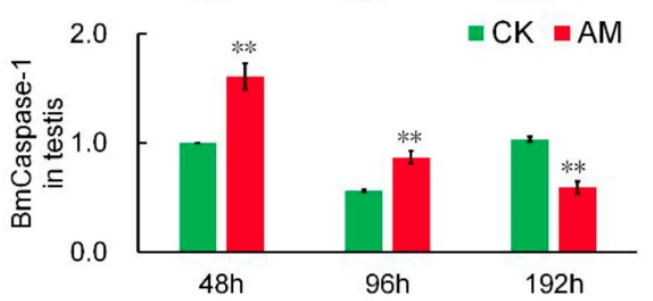

Figure 6. Hyperproteinemia triggers apoptosis. (a) TUNEL staining of silkworm gonad sections at $48 \mathrm{~h}$ after modeling. (b-e) mRNA levels of apoptosis-related genes BmDronc and BmCaspase- 1 in gonad cells from silkworm at 48-192 h after modeling. $* \mathrm{P}<0.05 ; * * \mathrm{P}<0.01$; n.s., no significant difference between the two groups. Bar $=100 \mu \mathrm{m}$. Red represents apoptotic cells. 


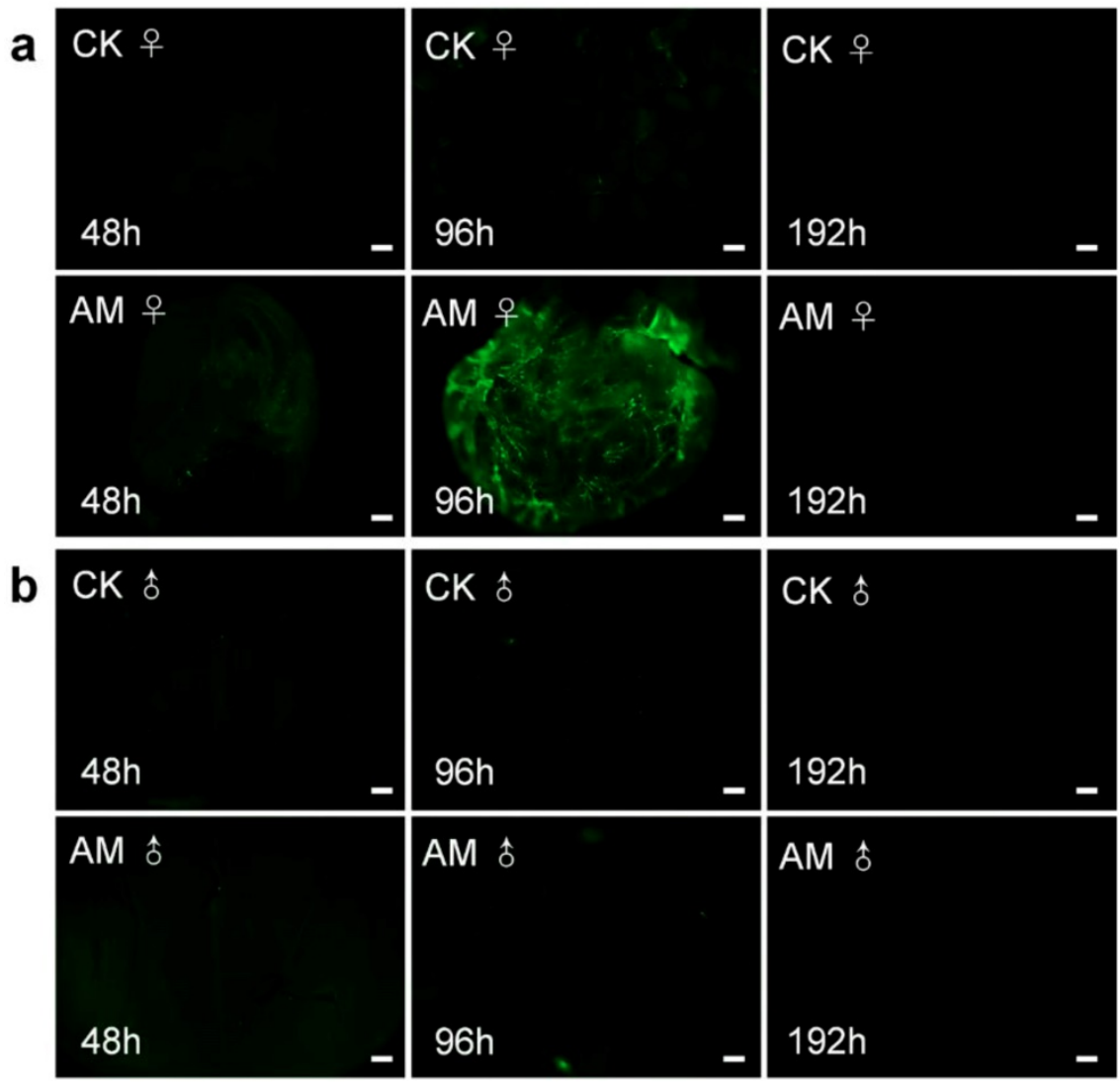

Figure 7. Impact of hyperproteinemia on reactive oxygen species in silkworm (a) ovary and (b) testis. Bar $=200 \mu \mathrm{m}$.

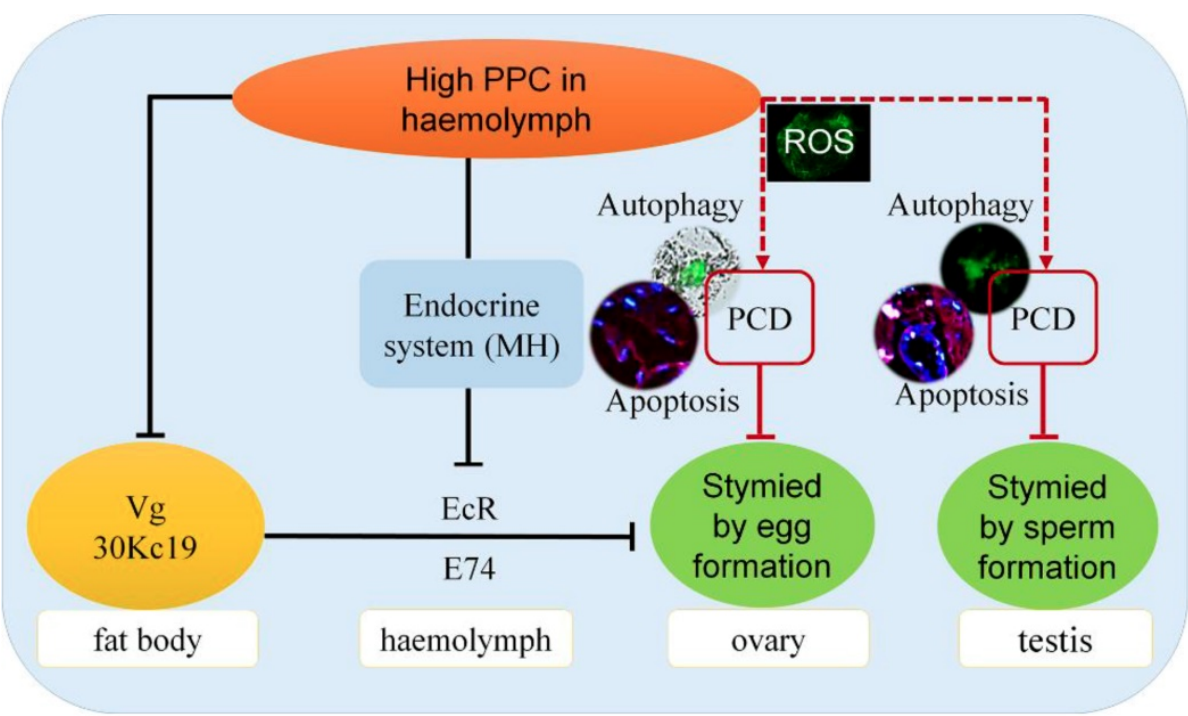

Figure 8. Impacts of hyperproteinemia on gonad development in male and female silkworms.

\section{Hyperproteinemia affects reproductive development via the endocrine system in silkworms}

The main proteins in silkworm eggs include vitellin (Vt, 40\%), 30K (35\%) and egg-specific protein $(25 \%) . \mathrm{Vg}$ is a precursor of $\mathrm{Vt}$, and $\mathrm{Vg}$ and $30 \mathrm{~K}$ are synthesized by fat bodies and secreted into the hemolymph, from where they are absorbed and accumulate in the ovaries [57,58]. Germ cells in the ovary have been shown to take up $\mathrm{Vg}$ via endocytosis mediated by VgR in the cell membrane in Drosophila melanogaster [59], Aedes aegypti [60], and B. mori [61]. The ecdysteroid, molting hormone $(\mathrm{MH})$, regulates the uptake of $\mathrm{Vt}$ by oocytes through dual control of the EcR in the hemolymph and the early response gene E74 [60,62-64], and induces transcription of $\mathrm{Vg}$ in female silkworm fat bodies [61]. Disruption of EcR function has also been reported to affect the growth of 
ovaries, oocytes, and eggs [65-67]. The Vg protein can play an important role in female reproductive development in B. mori by inhibiting $\mathrm{Vg}$ expression and thus adversely affecting egg formation and embryo development [68].

We recently showed that a high PPC environment hindered remodeling of the fat body, as the main metabolic tissue in the silkworm, though this phenotype could be largely rescued by the active ingredient of exogenous $\mathrm{MH}, 20 \mathrm{E}$ [19]. In the current study we showed that high PPC inhibited the synthesis of $\mathrm{Vg}$ and $30 \mathrm{~K}$ in female fat bodies, and may further inhibit the expression of $\mathrm{VgR}$ in ovarian cells via the $\mathrm{MH}$ pathway, thus preventing the transport and accumulation of proteins essential for ovarian development (Fig. 8).

\section{Conclusion}

High PPC inhibits the synthesis of $\mathrm{Vg}$ and $30 \mathrm{~K}$, which are required for the development of ovaries in female B mori. High PPC is transported through the hemolymph to the gonads and induces PCD in testis and ovary cells, slows the development of germ cells, and significantly reduces the reproductive coefficient. The reproductive toxicities of high PPC differ in terms of intensity and mechanism between the sexes.

\section{Supplementary Material}

Supplementary figures and tables.

http://www.ijbs.com/v15p2170s1.pdf

\section{Acknowledgements}

This work was supported by the National Natural Science Foundation of China (Grant No. 31672492), the Provincial Key R \& D Program of Jiangsu (Grant No. BE2015317), the China Agriculture Research System (CARS) (Grant No. CARS-22), the Priority Academic Program Development of Jiangsu Higher Education Institutions (PAPD), and the Postgraduate Research \& Practice Innovation Program of Jiangsu Province (Grant No. KYCX17_2031, No. KYCX19_1977). The funders had no role in study design, data collection and analysis, decision to publish, or preparation of the manuscript. The manuscript was edited by a native English speaker of International Science Editing Scientific Services.

\section{Author Contributions}

S.Q.Xu and X.D.Chen, Y.F.Wang conceived this project. Y.F.Wang, X.D.Chen, G.Wang, Q.Y. Li, X.Y. Liang and Y.H. Sima performed the research. Y.F.Wang, X.D.Chen and S.Q.Xu analyzed the data and wrote the paper. All authors participated in the revision of this paper.

\section{Additional Information}

We declare that we have no competing interests.

\section{Competing Interests}

The authors have declared that no competing interest exists.

\section{References}

1. Kittisakmontri K, Reungrongrat S, Lao-Araya M. Hypoalbuminaemia at admission predicts the poor outcomes in critically ill children. Anaesthesiol Intensive Ther. 2016; 48(3):158-61.

2. Zusman O, Farbman L, Tredler Z, Daitch V, Lador A, Leibovici L, Paul M. Association between hypoalbuminemia and mortality among subjects treated with ertapenem versus other carbapenems: prospective cohort study. Clin Microbiol Infect. 2015; 21(1):54-8.

3. Chen CW, Chen YY, Lu CL, Chen SC, Chen YJ, Lin MS, Chen W. Severe hypoalbuminemia is a strong independent risk factor for acute respiratory failure in COPD: a nationwide cohort study. Int J Chron Obstruct Pulmon Dis. 2015; 10:1147-54.

4. Horowitz IN, Tai K. Hypoalbuminemia in critically ill children. Arch Pediatr Adolesc Med. 2007; 161(11):1048-52.

5. Narnaware SD, Ghorui SK, Kumar S, Patil NV. Vertical transmission of Trypanosoma evansi in dromedary camels and studies on fetal pathology, diagnosis and treatment. Acta Parasitol. 2016; 61(2):329-36.

6. Bernardini D, Gerardi G, Contiero B, Caldin M. Interference of haemolysis and hyperproteinemia on sodium, potassium, and chloride measurements in canine serum samples. Vet Res Commun. 2009; 33(1):173-6.

7. Manning RD Jr. Chronic effects of hyperproteinemia on blood volume and lymph protein concentration. Am J Physiol. 1992, 262(4 Pt 2):H937-41.

8. Nordon J. Letter: Hyperproteinaemia. Med J Aust. 1974; 1(12):456.

9. Olivero JJ. Case in point. Pseudohyponatremia due to hyperproteinemia in multiple myeloma. Hosp Pract (Off Ed). 1994; 29(8):61.

10. Rubiés-Prat J. Chronic kidney failure, hyperproteinemia and vascular risk. Med Clin (Barc). 1984; 83(4):173-5. (In Spanish).

11. Cattan R, Vesin P, Hirsch-Marie H. Cirrhosis with hyperproteinemia. Further clinical and biological studies. Sem Hop. 1961; 37:2714-7 (In French).

12. Matuszak J. A case of hepatic cirrhosis with hyperproteinemia and beta-2M-macroglobulinemia diagnosed after infectious hepatitis. Przegl Lek. 1967; 23(7):586-7.

13. Schneiderbaur A, Rettenbacher F. Hyperproteinemia and macroglobulinemia in liver cirrhosis. Wien Med Wochenschr. 1970; 120(6):93-6.

14. Adeyeba OA. Hyperproteinaemia in Dracunculiasis. Int J Zoonoses. 1985; 12(2):150-1.

15. Meléndez-Lazo A, Ordeix L, Planellas M, Pastor J, Solano-Gallego L. Clinicopathological findings in sick dogs naturally infected with Leishmania infantum: Comparison of five different clinical classification systems. Res Vet Sci. $2018 ; 117: 18-27$.

16. Manning RD Jr. Chronic lymph flow responses to hyperproteinemia. Am J Physiol. 1998; 275(1 Pt 2):R135-40.

17. Riemer F, Kuehner KA, Ritz S, Sauter-Louis C, Hartmann K. Clinical and laboratory features of cats with feline infectious peritonitis- a retrospective study of 231 confirmed cases (2000-2010). J Feline Med Surg. 2016; 18(4):348-56.

18. Magid JH. Chronic hyperproteinemia associated with a probable abdominal abscess in an Appaloosa stallion. Vet Clin North Am Equine Pract. 2006; 22(1):53-60.

19. Chen XD, Wang YF, Wang YL, Li QY, Ma HY, Wang L, Sima YH, Xu SQ. Induced hyperproteinemia and its effects on the remodeling of fat bodies in silkworm, Bombyx mori. Front Physiol. 2018; 9:302.

20. Perondi F, Brovida C, Ceccherini G, Guidi G, Lippi I. Double filtration plasmapheresis in the treatment of hyperproteinemia in dogs affected by Leishmania infantum. J Vet Sci. 2018; 19(3):472-6.

21. Bartelheimer H, Schwartzkopff W. Fractionated studies on tissue juice. V. Comparative quantitive and electrophoretic determinations of proteins in normo-, hypo-, and hyperproteinemia. Z Gesamte Exp Med. 1954; 122(5):478-96.

22. Simón L, Funes AK, Yapur MA, Cabrillana ME, Monclus MA, Boarelli PV, Vincenti AE, Saez Lancellotti TE, Fornés MW. Manchette-acrosome disorders during spermiogenesis and low efficiency of seminiferous tubules in hypercholesterolemic rabbit model. Plos One. 2017; 12(2):e0172994.

23. Saez Lancellotti TE, Boarelli PV, Monclus MA, Cabrillana ME, Clementi MA, Espínola LS, Cid Barría JL, Vincenti AE, Santi AG, Fornés MW. Hypercholesterolemia impaired sperm functionality in rabbits. PLoS One. 2010; 5(10):e13457.

24. Yamamoto $\mathrm{Y}$, Shimamoto $\mathrm{K}$, Sofikitis $\mathrm{N}$, Miyagawa I. Effects of hypercholesterolaemia on Leydig and Sertoli cell secretory function and the overall sperm fertilizing capacity in the rabbit. Hum Reprod. 1999; 14(6):1516-21.

25. Frank LA, Sutton-McDowall ML, Gilchrist RB, Thompson JG. The effect of peri-conception hyperglycaemia and the involvement of the hexosamine 
biosynthesis pathway in mediating oocyte and embryo developmental competence. Mol Reprod Dev. 2014; 81(5):391-408.

26. Frantz E, Menezes HS, Lange KC, Abegg MP, Correa CA, Zangalli L, Vieira JL, Zettler CG. The effect of maternal hypercholesterolemia on the placenta and fetal arteries in rabbits. Acta Cir Bras. 2012; 27(1):7-12.

27. Kevorkova O, Ethier-Chiasson M, Lafond J. Differential expression of glucose transporters in rabbit placenta: effect of hypercholesterolemia in dams. Biol Reprod. 2007; 76(3):487-95.

28. Farrar D, Simmonds M, Bryant M, Sheldon TA, Tuffnell D, Golder S, Dunne F, Lawlor DA. Hyperglycaemia and risk of adverse perinatal outcomes: systematic review and meta-analysis. BMI. 2016; 354:i4694.

29. Kilarkaje N, Al-Bader MM. Diabetes-induced oxidative DNA damage alters p53-p21CIP1/Waf1 signaling in the rat testis. Reprod Sci. 2015; 22(1):102-12.

30. Jangir RN, Jain GC. Diabetes mellitus induced impairment of male reproductive functions: a review. Curr Diabetes Rev. 2014; 10(3):147-57.

31. Tabunoki H, Bono H, Ito K, Yokoyama T. Can the silkworm (Bombyx mori) be used as a human disease model? Drug Discov Ther. 2016; 10(1):3-8.

32. Xing R, Chen XD, Zhou YF, Zhang J, Su YY, Qiu JF, Sima YH, Zhang KQ, He Y, $\mathrm{Xu}$ SQ. Targeting and retention enhancement of quantum dots decorated with amino acids in an invertebrate model organism. Sci Rep. 2016; 6:19802.

33. Nwibo DD, Hamamoto H, Matsumoto Y, Kaito C, Sekimizu K. Current use of silkworm larvae (Bombyx mori) as an animal model in pharmaco-medical research. Drug Discov Ther. 2015; 9(2):133-5.

34. Yan SQ, Xing R, Zhou YF, Li KL, Su YY, Oiu JF, Zhang YH, Zhang KO He Y, $\mathrm{Lu} \mathrm{XP}, \mathrm{Xu}$ SQ. Reproductive toxicity and gender differences induced bycadmium telluride quantum dots in an invertebrate model organism. Sci Rep. 2016; 6:34182.

35. Matozzo V, Marin M G. Can 4-nonylphenol induce vitellogenin-like proteins in the clam Tapes philippinarum? Environmental Research, 2005; 97(1):43-49.

36. Han C, Chen E, Shen G, Peng Z, Xu Y, Zhang H, Liu H, Zhang Y, Wu J, Lin $Y, X i a$ Q. Vitellogenin receptor selectively endocytoses female-specific and highly-expressed hemolymph proteins in the silkworm Bombyx mori. Biochemistry \& Cell Biology-biochimie Et Biologie Cellulaire, 2017; 95(4):510-516.

37. Lin Y, Meng Y, Wang Y X, Luo J, Katsuma S, Yang CW, Banno YM, Kusakabe T, Shimada T, Xia QY. Vitellogenin Receptor Mutation Leads to the Oogenesis Mutant Phenotype "scanty vitellin" of the Silkworm, Bombyx mori. Journal of Biological Chemistry, 2013; 288(19):13345-55.

38. Yuan H, Li Z M, Shao J, Ji WX, Xia W, Lu S. FGF2/FGFR1 regulates autophagy in FGFR1-amplified non-small cell lung cancer cells. Journal of Experimental \& Clinical Cancer Research, 2017; 36(1):72.

39. Li K L, Zhang Y H, Xing R, et al. Different toxicity of cadmium telluride, silicon, and carbon nanomaterials against hemocytes in silkworm, Bombyx mori. Rsc Advances, 2017; 7(79):50317-27.

40. Liu WT, Lin $\mathrm{CH}$, Hsiao M, Gean PW. Minocycline inhibits the growth of glioma by inducing autophagy. Autophagy. 2011; 7(2):166-75.

41. Ji MM, Lee JM, Mon H, Iiyama $K$, Tatsuke $T$, Morokuma D, Hino M, Yamashita M, Hirata K, Kusakabe T. Lipidation of BmAtg8 is required for autophagic degradation of p62 bodies containing ubiquitinated proteins in the silkworm, Bombyx mori. Insect Biochem Mol Biol. 2017; 89:86-96.

42. Xie K, Tian L, Guo X, Li K, Li J, Deng X, Li Q Xia O Zhong Y, Huang Z, Liu J, Li S, Yang W, Cao Y. BmATG5 and BmATG6 mediate apoptosis following autophagy induced by 20-hydroxyecdysone or starvation. Autophagy. 2016; 12(2):381-96.

43. Gai Z, Zhang X, Islam M, Wang X, Li A, Yang Y, Li Y, Peng J, Hong H, Liu K. Characterization of Atg8 in lepidopteran insect cells. Arch Insect Biochem Physiol. 2013; 84(2):57-77.

44. Bohère J, Mancheno-Ferris A, Al Hayek S, Zanet J, Valenti P, Akino K, Yamabe Y, Inagaki S, Chanut-Delalande H, Plaza S, Kageyama Y, Osman D, Polesello C, Payre F. Shavenbaby and Yorkie mediate Hippo signaling to protect adult stem cells from apoptosis. Nat Commun. 2018; 9(1):5123.

45. Khan C, Muliyil S, Ayyub C, Rao BJ.The initiator caspase Dronc plays a non-apoptotic role in promoting DNA damage signalling in D. melanogaster. J Cell Sci. 2017; 130(18):2984-95.

46. Zhou S, Hong $\mathrm{O}, \mathrm{Li}$ Y, Li O, Wang M. Autophagy contributes to regulate the ROS levels and PCD progress in TMV-infected Tomatoes. Plant Science, 2018; 269:12-19.

47. Pormehr M, Ghanati F, Sharifi M, McCabe PF, Hosseinkhani S, Zare-Maivan $\mathrm{H}$. The role of SIPK signaling pathway in antioxidant activity and programmed cell death of tobacco cells after exposure to cadmium. Plant Sci. 2019; 280:416-23.

48. Yu J, Li S, Qi J, Chen Z, Wu Y, Guo J, Wang K, Sun X, Zheng J. Cleavage of GSDME by caspase-3 determines lobaplatin-induced pyroptosis in colon cancer cells. Cell Death Dis. 2019; 10(3):193.

49. Cnop M, Welsh N, Jonas J C, Jörns A, Lenzen S, Eizirik DL. Mechanisms of pancreatic beta-cell death in type 1 and type 2 diabetes: many differences, few similarities. Diabetes. 2005; 54 (2):S97-107.

50. Du D, Hu L, Wu J, Wu Q, Cheng W, Guo Y, Guan R, Wang Y, Chen X, Yan X, Zhu D, Wang J, Zhang S, Guo $Y$, Xia C. Neuroinflammation contributes to autophagy flux blockage in the neurons of rostral ventrolateral medulla in stress-induced hypertension rats. J Neuroinflammation. 2017; 14(1):169.

51. Zheng WL, Wang BJ, Wang L, Shan YP, Zou H, Song RL, Wang T, Gu JH, Yuan Y, Liu XZ, Zhu GQ, Bai JF, Liu ZP, Bian JC. ROS-mediated cell cycle arrest and apoptosis induced by zearalenone in mouse sertoli cells via ER stress and the ATP/AMPK pathway. Toxins (Basel). 2018; 10(1). pii: E24.
52. Wang B, Huang J, Li J, Zhong Y. Control of macrophage autophagy by miR-384-5p in the development of diabetic encephalopathy. Am J Transl Res. 2018; 10(2):511-8.

53. Fan L, Yin S, Zhang E, Hu H. Role of p62 in the regulation of cell death induction. Apoptosis. 2018; 23(3-4):187-93.

54. Calabrese EJ, Iavicoli I, Calabrese V. Hormesis: its impact on medicine and health. Hum Exp Toxicol. 2013; 32(2):120-52.

55. Hamacher-Brady A, Brady NR, Gottlieb RA. Enhancing macroautophagy protects against ischemia/reperfusion injury in cardiac myocytes. J Biol Chem. 2006; 281(40):29776-87.

56. Li L, Tan J, Miao Y, Lei P, Zhang Q. ROS and Autophagy: Interactions and molecular regulatory mechanisms. Cell Mol Neurobiol. 2015; 35(5):615-21.

57. Roth TF, Cutting JA, Atlas SB. Protein transport: a selective membrane mechanism. J Supramol Struct. 1976; 4(4):527-48.

58. Matozzo V, Gagné F, Marin MG, Ricciardi F, Blaise C. Vitellogenin as a biomarker of exposure to estrogenic compounds in aquatic invertebrates: a review. Environ Int. 2008; 34(4):531-45.

59. Richard DS, Gilbert M, Crum B, Hollinshead DM, Schelble S, Scheswohl D. Yolk protein endocytosis by oocytes in Drosophila melanogaster: immunofluorescent localization of clathrin, adaptin and the yolk protein receptor. J Insect Physiol. 2001; 47(7):715-723.

60. Zhu J, Chen L, Raikhel AS. Distinct roles of Broad isoforms in regulation of the 20-hydroxyecdysone effector gene, vitellogenin, in the mosquito Aedes aegypti. Mol Cell Endocrinol. 2007; 267(1-2):97-105.

61. Yang C, Lin Y, Shen G, Chen E, Wang Y, Luo J, Zhang H, Xing R, Xia Q. Female qualities in males: vitellogenin synthesis induced by ovary transplants into the male silkworm, Bombyx mori. Biochem Biophys Res Commun. 2014; 453(1):31-6.

62. Gilbert LI, Serafin RB, Watkins NL, Richard DS. Ecdysteroids regulate yolk protein uptake by Drosophila melanogaster oocytes. J Insect Physiol. 1998; 44(7-8):637-44.

63. Sun G, Zhu J, Chen L, Raikhel AS. Synergistic action of E74B and ecdysteroid receptor in activating a 20-Hydroxyecdysone effector gene. Proc Natl Acad Sci U S A. 2005; 102(43):15506-11.

64. Liu X, Dai F, Guo E, Li K, Ma L, Tian L, Cao Y, Zhang G, Palli SR, Li S. 20-Hydroxyecdysone (20E) primary response gene E93 modulates 20E signaling to promote Bombyx larval-pupal metamorphosis. J Biol Chem. 2015; 290(45):27370-83.

65. Hodin J, Riddiford LM. The ecdysone receptor and ultraspiracle regulate the timing and progression of ovarian morphogenesis during Drosophila metamorphosis. Dev Genes Evol. 1998; 208(6):304-17.

66. Takeuchi H, Paul R K, Matsuzaka E, Kubo T. EcR-A expression in the brain and ovary of the honeybee (Apis mellifera L.). Zoolog Sci. 2007; 24(6):596-603.

67. Yuan HX, Xu X, Sima $\mathrm{YH}, \mathrm{Xu}$ SQ. Reproductive toxicity effects of 4-nonylphenol with known endocrine disrupting effects and induction of vitellogenin gene expression in silkworm, Bombyx mori. Chemosphere. 2013; 93(2):263-8.

68. Yang C, Lin Y, Liu H, Shen G, Luo J, Zhang H, Peng Z, Chen E, Xing R, Han C, Xia Q. The Broad Complex isoform 2 (BrC-Z2) transcriptional factor plays a critical role in vitellogenin transcription in the silkworm Bombyx mori. Biochim Biophys Acta. 2014; 1840(9):2674-84 